\title{
A structured approach to medical comanagement of surgical patients
}

\section{Un approccio strutturato al comanagement medico dei pazienti chirurgici}

\author{
Eric Siegal*
}

Medical Director, Critical Care Medicine, Aurora St Luke's Medical Center, Milwaukee, Wisconsin, USA

Received 8 February 2012; accepted 21 March 2012

Available online 28 June 2012

\section{KEY WORDS}

Medical comanagement;

Hospitalism;

Medical consultation.

\begin{abstract}
Summary Comanagement is defined as shared responsibility, authority and accountability for the management of a hospitalized patient, and represents a fundamentally different model from traditional medical consultation. Medical comanagement has rapidly proliferated and is now a dominant model of care in American hospitals. Comanagement is most effective when patients are appropriately selected, processes are predetermined and systems are implemented to ensure rigorous and continuous improvement. This article provides a structured approach for conceptualizing and implementing medical comanagement.
\end{abstract}

(c) 2012 Elsevier Srl. All rights reserved.

\section{Introduction}

The director of orthopedic surgery at your hospital asks you to consider providing medical comanagement for hospitalized orthopedic patients. He has read that comanagement may improve the care of his patients, who are increasingly elderly and medically complicated. How should you respond? How do you determine if the request is reasonable, the resources you will need to succeed and the outcomes that you should target?

\section{Background}

Comanagement occurs when two or more physicians representing different specialties share responsibility, authority and accountability for the management of hospitalized patients [1]. It is fundamentally different from traditional medical consultation where an attending physician assumes primary responsibility for the patient while the consultant limits his involvement to a specific problem and remains subordinate to that attending physician. As comanagement often affects longstanding practice relationships by altering chains of command and care processes, it is important to carefully consider its implications and implement policies and procedures that maximize the likelihood of achieving positive outcomes.

Comanagement generally develops in three distinct ways. It may evolve as a logical consequence of a longstanding working relationship between departments that wish to collaborate in a more structured manner to improve the care of

\footnotetext{
* Corresponding author: Critical Care Medicine, Aurora St Luke's Medical Center, 2900 W, Oklahoma Ave., Milwaukee, WI 53215, USA. E-mail: esiegal67@gmail.com (E. Siegal).
} 
a cohort of patients. It may be instituted by fiat by a hospital administrator or department chair who mandates comanagement as a solution for service, quality or other performance deficiencies. Finally, comanagement may develop seemingly accidentally; a classic example is a medical service that initially manages high-risk hip fracture patients, but over time assumes responsibility for most if not all hospitalized orthopedic patients, irrespective of their diagnoses or medical comorbidities.

The rapid proliferation of medical comanagement in the United States is not surprising given recent trends in the American health care system [2]. Hospitalized patients are becoming older, sicker and more medically complex, necessitating greater input from physicians with medical expertise and consistent and rapid availability at the bedside. Surgeons and specialists are increasingly eager to focus their practices, reduce their workloads and allocate greater time to performing financially lucrative procedures. Hospital administrators, under pressure to contain costs, improve quality of care and retain high-demand specialists, often encourage medical comanagement to facilitate these ends. Finally, increasingly stringent workload restrictions on medical trainees have prompted academic and teaching hospitals to implement comanagement to reduce clinical demands on surgical and specialty teaching services.

Although comanagement was initially conceived to coordinate and improve care for high-risk, medically complex surgical patients, its scope in the United States has broadened to the point that many surgical patients are now primarily admitted to hospitalist or medical services, with surgeons effectively functioning as consultants. Consequently, hospitalists and other medical physicians are increasingly becoming de facto attending physicians for patients with acute surgical diagnoses [3]. The benefits of this new model of care remain unclear.

\section{Evidence}

The evidence supporting the impact of medical comanagement on quality, efficiency and cost of care is limited and mixed. While small cohort and retrospective studies have demonstrated that medical comanagement of surgical patients modestly reduces length of stay (LOS) and cost without adversely impacting quality or outcomes [4,5], no studies have demonstrated substantial impacts upon patient outcomes [6]. The single prospective, randomized trial of surgical comanagement to date demonstrated that medical comanagement of orthopedic patients undergoing joint replacement surgery reduced the incidence of minor complications (such as the incidence of urinary tract infections) but did not reduce major complications or mortality [7]. Nurses and orthopedic surgeons significantly favored comanagement over the standard model of care ${ }^{7}$, and anecdotal evidence suggests that this is a common outcome. Recent studies also suggest that the benefits of medical comanagement may be limited to high-risk surgical patients with complex medical or care coordination issues $[4,8,9]$. Although far more research is needed, the limited available evidence suggests that comanagement generally does not change important patient outcomes and that benefits may be restricted to selected high-risk patient populations.

\section{Risks and benefits}

The dramatic expansion of medical comanagement in American hospitals suggests that despite a paucity of evidence, there is widespread belief that comanagement positively impacts hospital operations, provider satisfaction and patient outcomes. However, it is also clear that medical comanagement can introduce new risks into patient care that can be categorized as follows.

\section{Complexity}

Adding a medical physician to a process that was historically managed by a single surgeon or specialist increases the complexity of that process. Adding complexity increases sophistication and adaptability, but it also increases errors and system failures. Adding a comanaging service to a care process can increase miscommunication between providers, patients and hospital staff, engender duplication of effort by medical and surgical teams, and obfuscate responsibility or accountability for performing important clinical tasks. For the medically complex surgical patient, it is reasonable to believe that the expertise and oversight afforded by a comanaging internist supersedes the risks imposed by adding complexity to the care. The same may not hold true when medical physicians comanage relatively healthy surgical patients whose medical issues are limited or straightforward.

\section{Scope of practice}

When medical physicians comanage a broad spectrum of surgical and specialty patients, they may confront conditions and complications that lie well outside of their training and experience. This phenomenon was recognized over a decade ago, when American hospitalists reported mismatches between what they learned in training and what they actually encountered in practice, notably in acute neurology, neurosurgery, orthopedics, general surgery and psychiatry $[10,11]$. Medical comanagement is also often subject to "mission creep", a term originally coined by the military to describe the inadvertent evolution of a mission beyond its original intent, often with disastrous consequences. As applied to comanagement, mission creep occurs when physicians initially comanage a carefully selected cohort of surgical patients with specific medical needs, but over time expand their services to other surgical patients, regardless of whether they are trained or qualified to do so.

\section{Career dissatisfaction}

In well-designed comanagement arrangements, physicians and surgeons work equitably under clearly and mutually defined rules of engagement, share responsibility for patients, and collaborate to improve care and learn from each other. However, it is easy for this relationship to become 
inequitable if surgeons expect medical teams to shoulder the "undesirable" portions of inpatient care, such as managing paperwork, holding family meetings and completing hospital discharge management. Hospital administrators often tacitly or overtly expect medical physicians to accept any and all comanagement referrals, irrespective of whether they are clinically appropriate. These behaviors can cement a perception that internists are subordinate members of the care team with limited control over what they do and how they do it, which may ultimately lead to job dissatisfaction and career burnout.

\section{Elements of successful comanagment programs}

Although there is no single approach to successful comanagement, effective comanagement programs share common features. The participants share a clear mission and definition of success, engage their stakeholders and set clear responsibilities and expectations for all parties. They proactively consider and address the potential pitfalls of the program, they identify the resources necessary to develop and sustain the program and they work to replicate successes. Finally, participants in successful comanagement programs continually examine and fine-tune their processes, strengthen internal and external relationships, build on successes and address their failures. The key elements of successful comanagement can be broken into seven general concepts:

1. Identify the rationale for comanagement and the expectations of key stakeholders

2. Select patients carefully

3. Ask tough questions

4. Clarify roles and responsibilities

5. Obtain resources and support

6. Measure performance

7. Revisit the relationship

\section{Identify the rationale for comanagement and the expectations of key stakeholders}

Before entering into any comanagement relationship, it is important to define the reasons driving the request, such as addressing quality deficiencies, improving clinical or financial outcomes, improving hospital efficiency, or redirecting clinical responsibilities to physicians who are best qualified to handle them. Clearly defining these goals clearly and obtaining broad buy-in from the participating parties is absolutely critical. After the basic premises have been clarified, one should identify who the key drivers are and how they expect to benefit as a result of comanagement. It is important to broadly define the stakeholders, as comanagement invariably impacts nursing staff, case managers, pharmacists, emergency departments and other hospital services. These secondary stakeholders should be engaged early in the development process to obtain their input and buy-in. Finally, it is vital to identify and reach out to skeptics, who are often are the first to identify legitimate concerns that may not be apparent to the program's champions.

\section{Select patients carefully}

As previously mentioned, medical comanagement probably most benefits patients whose medical or social comorbidities portend a higher risk for complications. Before entering a comanagement arrangement, it is important to predefine inclusion and exclusion criteria for comanagement and to ensure that all parties adhere to them. It is not uncommon for the "rules" to change based upon the personality of the physician or surgeon, the time of the day or the assessment of the triaging emergency physician.

\section{Ask tough questions:}

After goals and expectations have been clearly defined, it is imperative to reality-test them. There is nothing wrong with setting ambitious goals, but if some early "wins" cannot be demonstrated, the program will appear to underperform and will lose credibility and momentum. It is politically and operationally far easier to revise goals upward over time as the program gains maturity and sophistication than to scale them back after the program has failed to meet its targets. This is also the time to double check that the key stakeholders are sufficiently engaged and empowered to move the process forward and overcome obstacles that will inevitably arise during planning and implementation. Once reasonable expectations have been set and the stakeholders have been vetted, the next step is to explore the clinical and logistical risks posed by providing comanagement.

Consider carefully whether the comanaging physicians are uniformly qualified to provide the requested services. Internists generally have limited training in or exposure to surgical management, and their understanding of surgical complications and medical comanagement may be inadequate to the task. It is vital to define the competencies and limitations of the comanaging team and to set clear guidelines to ensure that all members consistently remain within those boundaries. If additional training is necessary to ensure that the comanagement team is uniformly competent to provide the desired care, this is the time to identify the deficits, procure training and commit to completing it.

Finally, this is also the time to consider the non-clinical stresses that comanagement may impose upon physicians. Despite being chronically understaffed, many American hospitalist programs are under constant pressure to add new comanagement responsibilities. Overstretching an understaffed program can degrade physician efficiency, jeopardize quality of care and ultimately harm physician morale and retention. It is important to consider the added workload that comanagement may add and mitigate the impact, whether by phasing in the program, initially limiting the physicians' responsibilities, or sharing duties with other teams that can provide similar coverage.

\section{Clarify roles and responsibilities}

The roles and responsibilities of each provider should be clarified, and adjudication of disagreements over the content or process of care should be determined up front. 
Responsibilities for routine activities, such as patient admission, discharge and daily rounds should agreed upon up front and clearly and consistently articulated to patients, families and hospital staff. At best, failure to proactively address these issues confuses and frustrates physicians, hospital staff, patients and families. At worst, it can lead to serious clinical errors.

It is also crucial to predetermine how acute problems and emergencies will be managed. Physicians and surgeons should agree up front who will address and manage the most common complications, leaving nurses with as little ambiguity as possible about which service to contact when they occur. For comanagement to succeed, surgeons must be confident that physicians will reliably address acute medical concerns and physicians must be assured that surgeons will be at the ready to manage acute surgical issues.

\section{Obtain resources and support}

The stakeholders should determine whether additional resources are necessary to facilitate the goals of comanagement. If reducing hospital length of stay is a key expectation of the program, it may be important to allocate additional case management resources to facilitate more efficient patient throughput. If the goal is to improve the accuracy of medication reconciliation at hospital discharge, adding pharmacy resources or upgrading electronic health records may be appropriate. If comanaging physicians are expected to spend a significant amount of time in a particular surgical unit, they may need dedicated workspace or computer terminals to facilitate efficient workflow. In the end, resources should be allocated to maximize the likelihood of the program achieving its goals.

\section{Measure performance}

The sixth critical factor in building and maintaining a successful co-management service is to have finite and measurable performance criteria to determine whether the program is actually delivering the expected results. Demonstrating success, especially early on, generates and maintains enthusiasm for the program, quiets naysayers, justifies ongoing support for the program and creates credibility for future endeavors. Early recognition of missed goals or errors creates confidence in the process and may ultimately protect patients from harm.

Measures should reflect outcomes that are achievable, specific, reliable and measurable. It is not uncommon to blend financial and operational measures (e.g. impact upon hospital cost, surgical efficiency, or length of stay) with quality measures (e.g. adherence to quality standards, infection or complication rates, or impact upon rehospitalization rates). Whatever the measures, they should be mutually supportive and internally consistent. For example, asking comanaging physicians to simultaneously reduce hospital length of stay and re-hospitalization rates may create conflicting incentives, as implementing an aggressive discharge policy may ultimately increase the likelihood of subsequent re-hospitalization.

\section{Revisit the relationship}

Finally, incorporate a process of regular re-evaluation into the relationship. Over time, a previously enthusiastic stakeholder may become disgruntled while the skeptic may become a convert. Problems that are thought to be trivial may fester if not proactively addressed. The three most important questions to ask are whether the program's goals are being met, whether the stakeholders are satisfied, and how the program is impacting patient care. It is far better to ask these questions proactively than wait for complaints to arrive.

\section{Summary}

The rapid proliferation of comanagement in American hospitals is unlikely to abate in the foreseeable future, and may become the dominant model of care for many surgical patients with medical comorbidities. While there are many roads to comanagement, effective programs share common traits and processes. Time spent up front thinking through the rationale, goals, risks and logistical hurdles will be more than repaid in time and effort saved trying to fix problems after they have emerged. Ultimately, however, the single most important question to ask is; "Would I want a loved one to have the care that we are proposing to provide?".

\section{Conflict of interest}

The author has no conflicts of interest to disclose.

\section{References}

[1] Siegal E. Just because you can doesn't mean that you should: A call for the rational application of hospitalist comanagement. J Hosp Med Sept 2008;3(5):398-402.

[2] Society of Hospital Medicine. The Society of Hospital Medicine 2005-2006 Survey: The Authoritative Source on the State of the Hospital Medicine Movement. Published by the Society of Hospital Medicine, 2006. Executive summary available at http:// www. hospitalmedicine.org/AM/Template.cfm?Section5Surveys2\&Template5/CM/ContentDisplay.cfm\&ContentID514352. Accessed.

[3] Gesensway D. Feeling pressure to admit surgical patients? Hospitalists work to set limits on co-management arrangements. Today's Hospitalist 2008.

[4] Pinzur MS, Gurza E, Kristopaitis T, Monson R, Wall MJ, Porter A, et al. Hospitalist-orthopedic co-management of high-risk patients undergoing lower extremity reconstruction surgery. Orthopedics 2009;32(7):495.

[5] Phy MP, Vanness DJ, Melton LJ, Schleck CD, Larson DR, Huddleston PM, et al. Effects of a hospitalist model on elderly patients with hip fracture. Arch Intern Med 2005;165: 796-801.

[6] Auerbach AD, Rasic MA, Sehgal N, Ide B, Stone B, Maselli J. Opportunity missed: medical consultation, resource use, and quality of care of patients undergoing major surgery. Arch Intern Med 2007;167(21):2338-44.

[7] Huddleston JM, Long KH, Naessens JM, Vanness D, Larson D, Trousdale R, et al. Medical and surgical comanagement after elective hip and knee arthroplasty; a randomized controlled trial. Ann Int Med 2004;141(1):28-38. 
[8] Southern WN, Berger MA, Bellin EY, Hailpern SM, Arnsten JH. Hospitalist care and length of stay in patients requiring complex discharge planning and close clinical monitoring. Arch Int Med 2007;167(17):1869-74.

[9] Simon TD, Eilert R, Dickinson LM, Kempe A, Benefield E, Berman S. Pediatric hospitalist comanagement of spinal fusion surgery patients. J Hosp Med 2007;2:23-9.
[10] Plauth WH, Pantilat SZ, Wachter RM, Fenton CL. Hospitalists' perceptions of their residency training needs: Results of a national survey. Am J Med 2001;111:247-54.

[11] Glasheen JJ, Epstein KR, Siegal E, Kutner J, Prochazka AV. The spectrum of community-based hospitalist practice: A call to tailor internal medicine residency training. Arch Intern Med 2007;167(7):727-8. 